\title{
Sobre los procesos de enseñanza-aprendizaje en el legado de los cantos de trabajo del llano, patrimonio cultural inmaterial de la Orinoquia
}

Teaching-Learning Processes in the Legacy of the Llano Work Songs, Intangible Cultural Heritage of the Orinoquia Region

\author{
HERNÁN RIVERA SALCEDO \\ FUNDACIÓN UNIVERSITARIA INTERNACIONAL DEL TRÓPICO AMERICANO - UNITRÓPICO \\ ALIDA CHAPARRO BARRERA \\ FUNDACIÓN UNIVERSITARIA INTERNACIONAL DEL TRÓPICO AMERICANO - UNITRÓPICO
}

Artículo recibido el / Article received: 2018-08-27

Artículo aceptado el / Article accepted: 2019-03-08

RESUMEN: Este artículo presenta un estudio sobre el proceso de enseñanzaaprendizaje de los cantos de trabajo del llano de la Orinoquia colombovenezolana, declarados en 2014 Patrimonio Cultural Inmaterial por el Ministerio de Cultura de Colombia y en 2017 Patrimonio Cultural Inmaterial de la Humanidad por la UNESCO. La metodología se desarrolla desde el paradigma cualitativo, de tipo descriptivo-interpretativo con enfoque en estudio de caso. Las técnicas cuanti-cualitativas fueron las encuestas y entrevistas semiestructuradas, además de la observación participante. La investigación se fija principalmente en el saber de los adultos mayores, denominados llaneros facultos, portadores de conocimientos ancestrales. Este estudio permitió estructurar propuestas de los procesos pedagógicos que se dan durante la enseñanza y aprendizaje de los cantos a través de la observación, imitación, repetición y memorización en contexto. Se concluye que es necesario resignificar, valorar y practicar las tradiciones culturales para que las nuevas generaciones las encuentren sentido y aplicabilidad.

Palabras clave: cantos de trabajo del Llano, portadores, llaneros facultos, plan de salvaguardia, saber ancestral

ABSTRACT: In this paper, we present a study on the teaching-learning process of the llano work songs of the Colombian-Venezuelan Orinoquia Region which were declared Intangible Cultural Heritage by the Ministry of Culture of Colombia in 2014 and as Cultural and Intangible World Heritage by UNESCO in 2017. The methodology is developed from the qualitative paradigm, descriptive-interpretive type with focus on case study. The quantitative-qualitative methods were the semistructured survey, the participant observation and the interview. The study was mainly focused on the elderly and carriers of ancestral knowledge, called Llaneros Facultos. This study allowed us to design proposals of the pedagogical processes that occur during the teaching and learning of the songs through of observation, 
imitation, repetition and memorization in context. We concluded that is necessary to re-signify, value and rescue the cultural heritage so that the new generations find meaning and applicability.

Keywords: Llano Work Songs, carriers of Ancestral Knowledge, Llaneros facultos, Safeguard plan, ancestral knowledge.

\section{INTRODUCCIÓN ${ }^{1}$}

Los cantos de trabajo del llano representan un conjunto de expresiones del universo cultural de la Orinoquía colombo-venezolana, declarados Patrimonio Cultural Inmaterial en riesgo y adoptados en el Plan Especial de Salvaguardia de Carácter urgente - PEScU -, por el Ministerio de Cultura de Colombia (Garcés et al., 2013: 11-14). Los cantos son versos sonoros que se usan durante el trabajo llanero para establecer relaciones de cercanía, afecto y acompañamiento entre el hombre y los animales. Dichos cantos se clasifican en cuatro modalidades: de ordeño, cabrestero, vela y domesticación; siempre van acompañados por gritos, silbos y japeos; se caracterizan por ser coplas inéditas e improvisadas que el trabajador entona a capela y en forma absolutamente libre y espontánea.

Los cantos de trabajo de llano, considerados un bien patrimonial inmaterial, contienen una carga simbólica que se da por el uso y afecto con que se entonan y utilizan, inclusive en los trabajos cotidianos. Son producto de experiencias propias de la región y hacen parte de las representaciones culturales de la sociedad que los identifica, revelan tradiciones y costumbres que conforman la memoria colectiva de los pueblos llaneros y constituyen una de las máximas expresiones de sus raíces.

\subsection{SOBRE EL ORIGEN DE LOS CANTOS DE TRABAJO DE LLANO EN AMÉRICA}

Salazar (2000: 119) sostiene que los cantos de trabajo del llano tienen influencia árabe hispánica, por cuanto la historia cuenta que «las primeras huellas del canto árabe preislámico, se descubren en el cantar nomadista (al hida) propio de los camelleros en la travesía de los desiertos»». Dichos camelleros utilizaban cantos o hudás para acompañar el paso de los camellos por el desierto; posteriormente tales cantos o lamentos se transformaron en ginás o cantos de una sola voz, los cuales se fueron convirtiendo en melodías complejas llamadas ramales; forma clásica del árabe, inspirada en el Corán y propia de la épica musulmana, razón por la cual, el tono y la estructura se ceñía más al verso poético recitado.

Hacia el siglo VIII, comienza la invasión árabe por el sur de España por el estrecho de Gibraltar, este encuentro de culturas facilita el entrelazado de costumbres, una fusión de experiencias que poco a poco se consolidan tanto, que hacen parte de las tradiciones propias de la región. Entre los siglos VIII y IX surge un nuevo estilo de estribillos

\footnotetext{
${ }^{1}$ Presentamos agradecimientos al Ministerio de Cultura de Colombia. A Unitrópico por el apoyo al proyecto de investigación, con recursos de la convocatoria interna No. 001. A la coordinación técnica de investigación, a investigadores de apoyo como la docente Deisy Robles Ortiz. A los portadores de los Cantos de Trabajo del Llano en los municipios de Maní, San Luís de Palenque, Trinidad, Orocué y Paz de Ariporo, en el departamento de Casanare - Colombia.
} 
llamados mawshaha y zéjel de donde surgen las primeras formas de versos en el mundo occidental, base de la canción popular que se conoce hoy (Salazar, 2000: 119).

La influencia de la cultura islámica en España dio origen a un desarrollo cultural e intelectual de la sociedad española que posteriormente con el descubrimiento de América generó un «proceso de transculturación que tuvo lugar de España a sus colonias» (Handal, 2004: 11).

Por el año 1563 ingresa por Venezuela el zamorano Juan Gaitero con más o menos tres mil carneros, se lee que conducía el rebaño haciendo uso de esas melodías hispanoárabes. Luego de su travesía, se asentó en Santiago de León de Caracas. Las históricas narraciones se han encargado de recordar que, probablemente, durante estos largos trayectos hayan surgido los cantos de arreo, que llegaron a los Llanos de Venezuela, allí se fundieron con los cantos propios de los indígenas que habitaban la zona y posteriormente por los avances migratorios se extendieron por los Llanos Orientales de Colombia y la parte occidental de Venezuela. Esa amalgama de expresiones, no solo refiere los cantos para el trabajo llanero, objeto de esta investigación, sino que surgen otras tonalidades que identifican la región de la Orinoquía.

\subsection{CANTOS DE TRABAJO DE LLANO EN Los Llanos ORIENTALES DE COLOMBiA}

Durante el siglo XVI, se reporta la numerosa llegada de personas a los llanos colombo-venezolanos procedentes de Castilla La Vieja, Andalucía, Castilla La Nueva y León de los territorios que hoy se conocen como España (Boyd-Bowman, 1963: 184186). Con ellos, posterior a la colonización, llegaron los esclavos provenientes de Asia y África. Estas migraciones confluyeron en una interacción entre pobladores que según Rivera Arenas (2009: 14) se denomina mezcla intercultural, un cruce de costumbres que conformaron una nueva cultura.

En la época de la Colonia en la historia de Colombia, aproximadamente hacia 1536 los pobladores peninsulares (Andalucía, Castilla La Vieja, León y Castilla La Nueva), así como otros extranjeros provenientes de Europa que llegaron a Venezuela, pasaron a las llanuras colombianas y trajeron algunos ejemplares bovinos para asentarlos y reproducirlos en las tierras que hoy hacen parte del territorio casanareño. Posteriormente, la ganadería se convertiría en el comienzo de una de las actividades económicas más significativas y que identifica a la región de los llanos orientales en Colombia.

Hacia el año 1662 los Jesuitas fundaron la primera hacienda en la región llamada Hacienda Caribabare, allí se inicia la crianza de rebaños de ganado bovino, equino y pastoril -carneros-, actividades que se constituyeron en fundamento para el nacimiento de la generación de vaqueros, quienes se ocupaban del oficio y cuidado de los animales. A la par se practicaban los cantos para las labores en el llano, los cuales se refirieron como cantos al ganado para calmar su ansiedad, su bravía y evitar la soledad en la sabana, la tristeza y hasta el maltrato de los dueños. La práctica constante de estos cantos indicaba que era la acción más adecuada y eficiente para lograr cercanía con los animales.

Años más tarde, la corona española ordena a los Jesuitas abastecer de carne de res al centro del Virreinato de la Nueva Granada, por tal motivo comenzaron los largos y fatigosos trayectos por las llanuras de la Orinoquia con grandes cantidades de ganado bajo la guía de los vaqueros, quienes para amortiguar el arduo trabajo y por la soledad del camino, recurrieron a la creatividad de los cantos para arriar y conducir el ganado. Al principio cantaban versos religiosos que fueron acomodando a las necesidades propias de la actividad, por lo que surgieron las cuatro variantes que en la actualidad hacen parte de la identidad de la cultura llanera, como bien dice Víctor Espinel «son cantos que sirven 
para tranquilizar a los animales» (Radio Nacional de Colombia, 2014) y confirma Pérez Radziunas (2014: 3):

[...]Los cantos de trabajo de Llano, más allá de su dimensión cultural como expresión inmaterial, representan un patrón de subsistencia que se basa en la relación hombreterritorio-ganado, a partir del cual las comunidades de los Llanos orientales construyeron sus estructuras sociales, económicas, culturales y espaciales.

Los siguientes versos son una muestra de Cantos de trabajo del llano que hoy se usan en algunos sectores de la Orinoquía Colombo-venezolana. Vale señalar que refiere cantos de ordeño, tonadas compuestas por Estévez y cantadas por Díaz (1976):

\author{
Lucerito 'e la mañana, \\ préstame tu claridad \\ para seguirle los pasos \\ a una ingrata que se va. \\ Mañana por la mañana \\ cubre tu patio de flores \\ que te viene a visitar \\ la Virgen de los Dolores.
} Clavelito, clavelito, clavelito, clavelito...

El canto de trabajo del llano se enraíza en los quehaceres habituales del trabajo, cuando los vaqueros sabanean el ganado -sabanear es andar- por la sabana, mientras arrean, tararean alegremente, a veces, entre una copla y otra, silban la melodía, que complementan con gritos que más parecen lamentos, son como suspiros alargados de melancolía; extendiendo la última vocal de la palabra final.

Gracias al canto, el llanero establece un vínculo afectivo con el ganado, porque canta cuando va a ordeñar, arrear, encorralar, canta para llamarlo y lo hace usando el nombre que él mismo le ha dado a la vaca o al becerro, siempre usa diferentes formas, letras y palabras como ya se ha comentado, ejemplo: oe, oe, oe, oe, oe, oe, mi vaquita orejona, oe, oe, oe, oe, oe, mi becerrito pintaooooo, los animales responden moviendo sus orejas y sus colas de un lado para otro, dan por recibidas esas expresiones de afecto y acercamiento que hace el hombre, entonces los animales se muestran dóciles, tranquilos; las vacas se dejan ordeñar sin estrés, los becerros se dejan recoger y amarrar, es decir se crea un ambiente de serenidad en el trabajo. En esta relación, el hombre está incorporando al animal en su propia historia, en su mundo cotidiano, es un acto humanizador que lo reconoce como parte esencial para su vida, por tanto, lo valora y respeta.

En este quehacer cotidiano, tan propio y particular de la región, cada trabajador se distingue por distintas habilidades vocálicas, que increíblemente los animales identifican, de manera que cuando escuchan alguna tonalidad cambian y van ajilándose $\mathrm{y}$ agrupándose, al tiempo, con los acordes de los cantos, como: o le-ri-le o je o; oh, oh oh..., se agrupan y acoplan tras una sencilla nota silbada, acompañada de una frase que considera al animal, le crea una especie de historia que inventan en forma inédita y particular, realmente son situaciones muy bellas exclusivas, propias de la región de llano abierto.

\title{
1.3. ¿POR QUÉ SE ESTÁ PERDIENDO ESTE CONOCIMIENTO?
}

Según Díaz (1994) en Cuenta y Canta, citado en González (2007: 41): 
Ya no se ve en estas tierras, el hombre que se entretiene cantándole y silbándole al llano, improvisando versos de amor, creando coplas llenas de vivencias y sabiduría. Ya no se ven madrinas de ganado, no se escucha ese cabrestero cantándole y ajilando el arreo entre el polvo. Ya no se escucha ese canto de esperanza por la alegría de ver nuevamente a la mujer que se besó en Paso Real. Ya no se arremolinan de noche, alrededor de una lamparita de kerosene, los arrieros a escuchar los cuentos picantes, a reír y cantar mientras en los corrales silenciosos los novillos descansan sus músculos y escuchan a sus mandadores.

Esta descripción se traduce como una preocupante amenaza a la manifestación cultural de los Cantos de Trabajo de Llano, porque los cambios que han suscitado las transformaciones socioeconómicas relacionadas con la redistribución y cambio de uso del suelo, la explotación de hidrocarburos, la diversificación productiva cuya base era la ganadería, el incremento de la urbanización y conformación de grandes ciudades, así como los periodos de violencia y desplazamiento en la región llanera están logrando la subvaloración y desuso de los cantos.

Adicionalmente, la forma de hacer ganadería ha cambiado, actualmente en su gran mayoría se utilizan motos para arriar el ganado, en otros casos solamente dos vaqueros se ocupan de conducirlo hasta abordar los camiones que los van a transportar siguiendo el trazado de las alambradas que tienen las fincas, poco importa el canto a capela de los hombres y menos el trato a los animales, mucho menos la amistad y la relación cálida que se puede dar con el animal, lo cual evidencia que estas costumbres vienen desapareciendo. Ahora, infortunadamente lo que en realidad interesa al hombre es la productividad económica, no importa si el animal sufre, si está cansado o angustiado, mucho menos el patrimonio que se pierde. Hoy se ordeña en forma mecánica, por tanto, no se necesita un acercamiento afectivo del hombre hacia el animal, todo lo hacen las máquinas destinadas para tal fin, quizás en algunas fincas con dueños jóvenes se coloca música instrumental cuando van a ordeñar, pero el canto del hombre se escucha muy poco (Gonzalez, 2012: 42).

En la medida en que se pierden estas prácticas, se olvidan los cantos que las acompañan y las costumbres que hacen parte de su idiosincrasia e historia que identifica a estas regiones. Se percibe un sentimiento de desconsuelo en los ganaderos antiguos que dan cuenta de esta pérdida, añoran esos versos, esos gritos y esa algarabía que hacía parte de la alegría y creatividad durante el trabajo, ellos creen que los cantos, están a punto de morir. Hoy, llegar a los llanos orientales colombianos y escuchar cantos de ordeño en las jornadas y en el trabajo cotidiano, produce un sentimiento de nostalgia indescriptible.

\subsection{MARCO INSTITUCIONAL}

A partir de la década del 70 y 80 , se expande el auge de las explotaciones de hidrocarburos en la región de la Orinoquia, un sinnúmero de campesinos se desplaza detrás del auge petrolero. Desafortunadamente, abandonan el campo, se orientan hacia otras posibilidades laborales que implican el olvido de lo propio - la razón de ser del llanero - por lo que muy pocas personas hoy realizan el trabajo propio del llano, lo cual trae como consecuencia la pérdida acelerada de costumbres y tradiciones de la cultura llanera. Además, los portadores con avanzada edad están muriendo y con ellos, también los saberes que reposan en su memoria, el sentido original que los ligaba a una forma de vida y sustento. En ese orden de ideas, la apropiación y limitación de las tierras en el llano, la redistribución de las tierras en los hatos, el incremento de la industrialización en la ganadería, la sobreexplotación de hidrocarburos, la inmersión de grupos armados al 
margen de la ley, los desplazamientos masivos, entre otros aspectos, están ocasionando el olvido de las raíces.

El Ministerio de Cultura de Colombia (2014: 6) ha realizado estudios sobre esta manifestación patrimonial con la resolución 0054, que adopta el PEScU, como patrimonio cultural inmaterial de la Nación. De otra parte, la Unesco (2017: 12) incluye la manifestación patrimonial de los cantos de trabajo de llano, en la lista de patrimonio cultural inmaterial de la humanidad, que requiere medidas de salvaguardia (Bortolotto, 2014: 7)

Por lo tanto, es indispensable adelantar gestiones pedagógicas e investigativas en las instituciones regionales, organizaciones sociales, culturales y académicas, para promover e impulsar acciones que conduzcan a reconocer y valorar la necesidad e importancia de recuperar y mantener el uso de esta riqueza oral patrimonial.

\section{2. ÁREA DE ESTUDIO Y POBLACIÓN DE IMPACTO}

Para adelantar esta investigación se seleccionaron cuatro (4) fincas, fundaciones y hatos ganaderos ubicados en el departamento de Casanare, Orinoquia de Colombia (figura 1). Fuente: Elaboración propia con base en los datos del Departamento Administrativo Nacional de Estadística [DANE] (2017).

\section{Figura 1. Mapa de ubicación de las fincas, fundaciones y hatos}

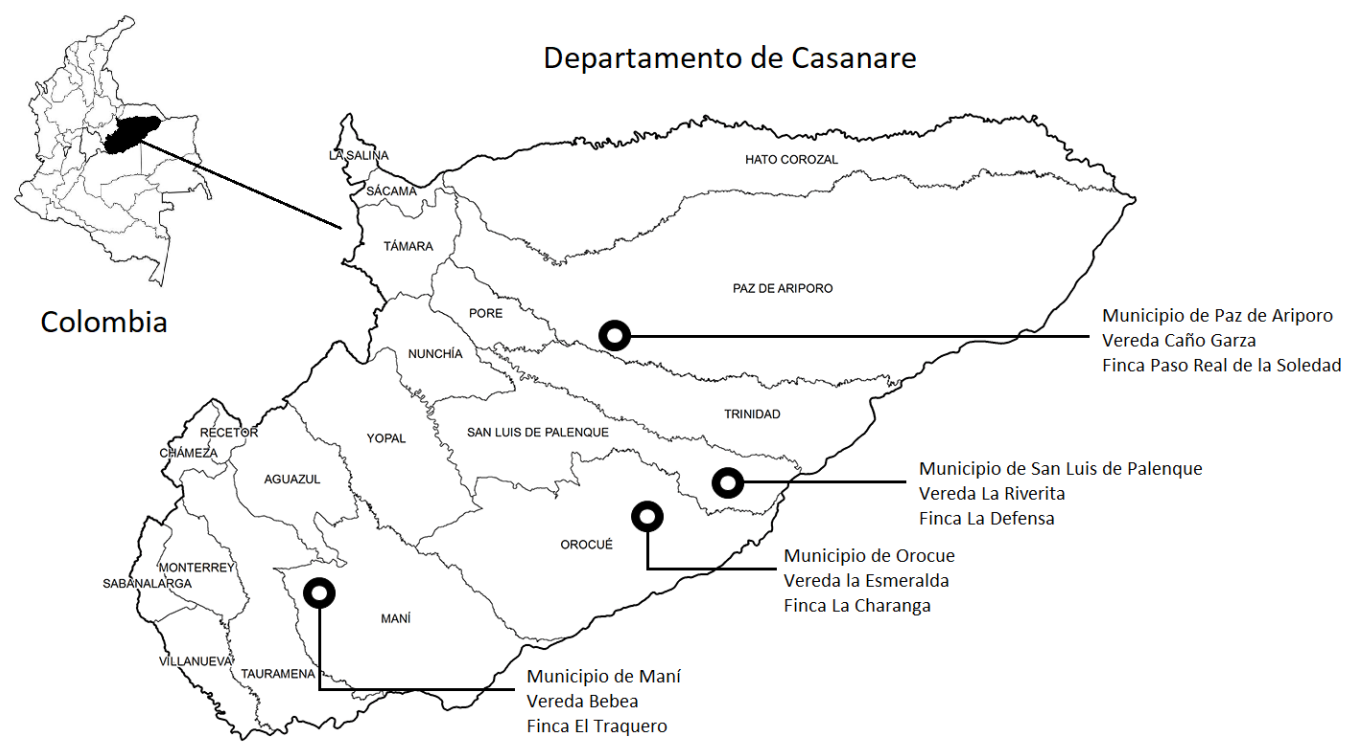

\section{PERSPECTIVA TEÓRICA}

La perspectiva teórica de este estudio plantea algunos postulados de la Teoría Conductista del Aprendizaje, que el psicólogo norteamericano Albert Bandura (1977) ha definido como aprendizaje por observación. Este tipo de aprendizaje centra el proceso en interacción del individuo con el entorno, es decir, el resultado del encuentro entre la persona con el medio en donde tiene contacto y cercanía. En este sentido, el aprendizaje de los cantos de trabajo del llano se da cuando el pequeño escucha a sus padres, o trabajadores y los acompaña a realizar las labores llaneras cotidianas como atajar, ordeñar y arrear ganado, observan cada acción, cada actividad que realizan diariamente, perciben 
el trato de amistad y conexión de las personas con los animales, se dan cuenta de cómo lo hacen, entonces están en la capacidad de extraer enseñanzas a partir de la observación.

No obstante, para ello también es indispensable la motivación, ver que las acciones de los mayores producen efectos positivos durante el trabajo sirve de estímulo para imitar y repetir esta forma de hacer el trabajo. No en vano, afirman Quintana, J. y Aparicio O. (2017:12), «la motivación, la contextualización [...] el interés, la curiosidad, [...] los ejemplos y las actividades auténticas, reales y cercanas son condiciones para lograr aprendizajes», tanto que aprende, interioriza y luego, el individuo reproduce lo aprendido; inclusive, lo mejora y enriquece. Por lo anterior, las prácticas que son objeto de este estudio, siguen un modelo conductista en la medida en que, de un condicionamiento originado en la observación, motivación, aceptación, valoración, memoria y refuerzo permanente, se produce el conocimiento.

Para llevar a cabo este proceso de aprendizaje (Bandura, 1986) se requiere: 1) prestar suficiente atención: porque para aprender algo es necesario estar a la expectativa frente las acciones caracterizadas por ser llamativas y estimulantes, 2) retención: para aprender es indispensable recordar, tener presente lo que se observa, se escucha y se percibe; cuando se recuerda se piensa, se imagina, 3) reproducción: que equivale a volver acciones lo observado, se logra cuando se recuerda, se imita, se repite, se crea, se recrea y se reproduce, 4) motivación: pues nada se hace, ni se aprende sin estimulo, por lo tanto, es necesario crear un ambiente propicio y atractivo para que los pequeños desarrollen el gusto por los cantos de trabajo de llano. La motivación es esencial para todo aprendizaje, ya sea como «motivación intrínseca», como refuerzo constante para que la repetición de dichas prácticas se constituya en acciones cotidianas naturales o hábitos propios del quehacer llanero o como «motivación extrínseca desde los intereses que provienen del exterior para la competitividad entre los compañeros» Martí, Contreras y Valls, Lafuente (2009: 4-5).

Con relación al aprendizaje significativo en la enseñanza de los cantos es fundamental recordar la propuesta de Ausubel (1963: 58) que considera que «el aprendizaje significativo es el mecanismo humano, por excelencia, para adquirir y almacenar la inmensa cantidad de ideas e informaciones representadas en cualquier campo de conocimiento». Como proceso hace posible una relación en forma estructurada los conocimientos que posee el individuo a partir de creencias y conceptos, con nueva información o nuevo conocimiento que ofrece el medio, la realidad, es una incorporación de conocimientos dinámica, práctica y no memorística. Para alcanzar un aprendizaje significativo se necesita según Contreras Oré (2016: 134), «Predisposición para el aprendizaje significativo, presentación de un material potencialmente significativo», es decir disposición para aprender y que las experiencias con las que interactúa el individuo brinden significado lógico y útil, de manera que se articule con los conocimientos que posee el individuo para que las pueda representar.

De acuerdo con lo expuesto, trabajar por el rescate de las costumbres ancestrales de la región de la Orinoquia colombo-venezolana exige que la enseñanza de los cantos sea un aprendizaje con sentido y significado, que las nuevas generaciones comprendan el conocimiento y uso de las tradiciones, los beneficios que aportan para el trabajo, el valor histórico que representan y la esencia como propiedad identitaria de la región, que la misma Unesco ha reconocido como patrimonio para restituir y conservar.

En consecuencia, se propone que la trasmisión de los cantos de trabajo de llano se dé a partir de las experiencias de cada llanero desde las vivencias cotidianas y la interacción con el medio, como una forma de aprendizaje significativo en donde el papel de los expertos y portadores del conocimiento actúen como mediadores y orientadores que, respetando la personalidad, espontaneidad y conocimientos previos de cada 
aprendiz, faciliten el desarrollo de habilidades para imaginar, crear los versos como producto de la relación con el entorno, los animales y las labores del llano, lo que en términos de Peris Reig (2017: 21) se logra a partir de dos facetas para enseñanza «la parte razonable y la parte sensible», de esta forma el aprendizaje permite a los niños, jóvenes o mayores, aprender en ambientes propicios en donde interactúan los conocimientos previos de cada individuo con nuevos conocimientos y vivencias que adquieren significado, teniendo «contacto directo con la realidad» Peris (2017: 26).

Tanto la propuesta de Albert Bandura como la de David Ausubel dan cuenta que para aprender se requiere de observación y esencialmente de motivación; la diferencia se encuentra en cuanto que en el aprendizaje significativo no basta la observación, imitación y repetición, sino que el individuo para aprender debe acomodar las nuevas oportunidades de conocimiento a las estructuras que ya posee con el fin de estar en capacidad de reproducirlas y aplicarlas en contexto, para el caso de los cantos de trabajo de llano deben presentar y contener argumentos de valor suficientes que despierte el interés de quienes quieren aprenderlos, practicarlos y mantenerlos.

\section{METODOLOGÍA}

El abordaje metodológico de la investigación es cualitativo, de carácter descriptivo e interpretativo, con enfoque etnográfico que posibilita la representación, exégesis y resignificación de los cantos de trabajo del llano, tanto como de las acciones que conforman la rutina de los llaneros portadores y sus familias. La naturaleza cualitativa está dada por la forma de aproximación al conocimiento ancestral de los cantos del trabajo del llano, teniendo en cuenta la diversidad semántica de las expresiones llaneras y el valor que poseen para los llaneros que las usan en los cantos de las faenas de trabajo del llano.

El enfoque etnográfico supone una mirada comprensiva de la realidad, la construcción colectiva de conocimiento para el encuentro, la interpretación de los significados, los sentidos y las percepciones de la población en el contexto.

Se aplicaron técnicas e instrumentos para la recolección de la información como: registro de trabajo de campo que da cuenta lo visto, vivido y expresado en las fincas, entrevistas y encuestas semiestructuradas que permitieron conocer lo que piensan y sienten quienes participaron de la investigación, comenzando por la observación participante que facilitó el contacto directo con la comunidad.

Gracias al análisis cualitativo y cuantitativo de las respuestas individuales obtenidas con la aplicación de los instrumentos mencionados, fue posible verificar los porcentajes y precisar las miradas de los encuestados con respecto a las preguntas propuestas, teniendo en cuenta que cada uno de los participantes expresaron sus ideas a partir de sus propias experiencias, sentimientos y emociones en forma libre y autónoma.

\subsection{PROCEDIMIENTO PARA LA BÚSQUEDA DE INFORMACIÓN}

El trabajo de campo se desarrolló en el escenario natural de las fincas seleccionadas, teniendo en cuenta sus características específicas: número de trabajadores, cantidad de ganado y disposición de los propietarios. Se precisa la interacción permanente entre sabana, esteros, morichales, ganado, caballo y hombre trabajador del llano. La población objetivo estuvo representada por 54 personas distribuidas así: tres (3) dueños de fincas, dieciséis (16) trabajadores de fincas, y treinta y cinco (35) portadores del conocimiento ancestral, de los cantos de trabajo de llano. Los criterios de selección fueron: edad de los participantes, relación directa con el trabajo de llano en las fincas, ser 
trabajador de finca, ser portador, disposición de los dueños de las fincas y voluntad de las personas seleccionadas.

Para reconocer y explorar los espacios en donde aún se practican los cantos de trabajo de llano se realizaron seis visitas a las fincas mencionadas. Las tres primeras salidas de campo se destinaron para el reconocimiento del contexto natural y para dicha acción se diseñó una guía de trabajo que permitió explorar los espacios relacionados con la extensión, ubicación, breve historia de las familias, las técnicas constructivas de las viviendas y anécdotas de las vivencias en el llano.

Para las siguientes visitas, se tuvieron en cuenta situaciones emergentes que surgieron de los primeros acercamientos y las cuales se abordaron a partir de diversos momentos, como: observación participante de los investigadores en el trabajo de llano que permite identificar y caracterizar dicha actividad y la relación directa entre el trabajador de llano y el ganado; registro de campo de actitudes, conversaciones, cantos, gritos, japeos, silbidos y demás formas de relacionarse entre los trabajadores, en el antes, durante y después de la faena llanera; además de la realización de registros video gráficos, fotográficos; finalmente aplicación de entrevistas y encuestas.

Las entrevistas y encuestas se aplicaron tanto a trabajadores como a portadores del conocimiento ancestral que se encontraban en las fincas seleccionadas, esto produjo un acercamiento real al objeto de estudio y enriqueció la interacción con las personas que hacen parte del entorno. Las preguntas se diseñaron con el fin de indagar por el cómo, el cuándo y el para qué se usaban los cantos, así como factores que influenciaron el aprendizaje de estos saberes y su reproducción en las faenas llaneras, igualmente, la mirada que cada uno de los participantes tenía de esas experiencias. Se encontró información valiosa sobre las prácticas propias del trabajo de llano, la manera como se interpretan y usan los cantos, el modo de vida de las personas que habitan las fincas y la forma de transmisión de los saberes a los niños y jóvenes.

\section{ANÁLISIS Y DISCUSIÓN}

El análisis se realizó a partir de la información obtenida con la aplicación de instrumentos aprobados para tal fin, los cuales permitieron detectar las formas como se ha dado el aprendizaje de los Cantos de Trabajo del Llano.

\subsection{ENSEÑANZA Y APRENDIZAJE DE LOS CANTOS}

Con relación a la pregunta: ¿Quiénes le enseñaron los cantos de trabajo de llano? el $32 \%$ manifestaron que aprendieron a través de sus padres y abuelos, aspecto representativo frente al proceso de integración de la familia con las actividades del trabajo en el llano. En cuanto a la incidencia de la formación en las pautas de crianza se cuenta un $26 \%$. El 20\% dan cuenta del aprendizaje de los cantos de manera empírica. La enseñanza de los cantos por los amigos, conocidos y vecinos y la costumbre como parte constitutiva en la enseñanza son factores adicionales que muestran que las relaciones de los portadores de los cantos de trabajo del llano y el proceso de socialización que se da en el entorno con otras personas y grupos sociales facilita la adquisición de este saber para interiorizarlo y asimilarlo como propio (Figura 2). 
Figura 2. Formas en que se transmitían los cantos de trabajo de llano

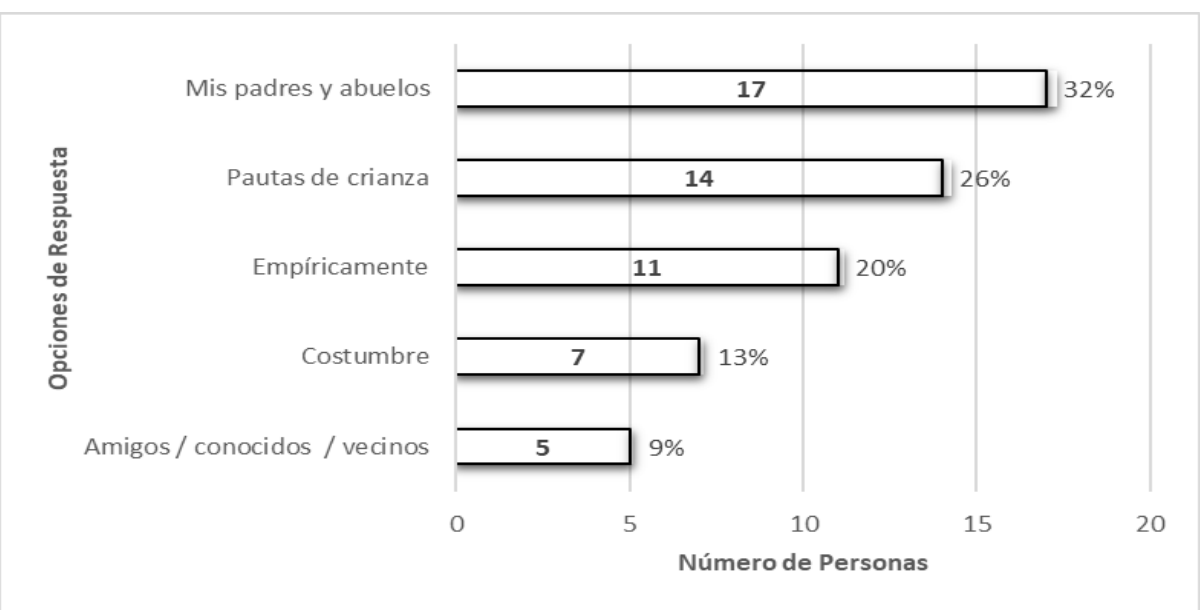

Respecto a la pregunta: ¿Cómo aprendieron los cantos de trabajo de llano? El $26 \%$ de los encuestados aprendieron desde el desarrollo de actividades prácticas diarias en las fincas, otro $22 \%$ aprendieron en una estrecha relación con el medio, es decir, realizando actividades de trabajo de llano en contexto. Su vinculación con el ganado y con los demás portadores o vaqueros es directa, lo cual permite la espontaneidad y la creación de composiciones que se originan por la interacción con el ganado, los caballos, ríos, caños y biodiversidad natural del entorno. Así mismo, se entiende que, desde el aprendizaje empírico, es decir, desde los hechos que ocurren y desde la observación directa, se asimilan los cantos con una representación del 20\%. En ese orden de ideas, los cantos se aprenden a partir del parafraseo practicando constantemente durante el trabajo diario (Figura 3).

\section{Figura 3. Espacios de aprendizaje de los cantos de trabajo de llano}

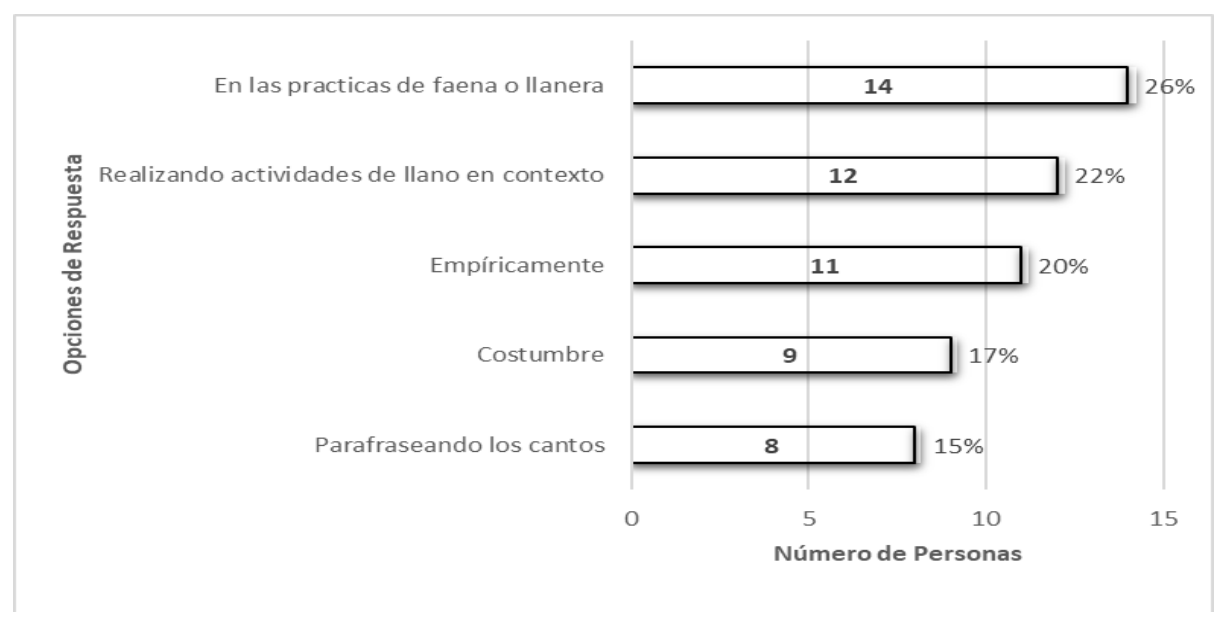

La enseñanza y el aprendizaje de las tradiciones y específicamente de los cantos de trabajo de llano se daba a partir de la experiencia sin preocuparse por la naturaleza del proceso, los padres enseñaban a sus hijos las actividades del trabajo de llano inicialmente acompañando, observando pero sobre todo practicando, para los papás no era necesario dar explicación teórica de dichas actividades, los acompañantes solamente repetían los 
cantos, silbidos y japeos, los memorizaban y utilizaban en el momento apropiado, de esta realidad surgen preguntas como: ¿ Hasta qué punto pueden enseñarse los cantos si el modelo práctico de los llaneros ha desaparecido?¿Cuán posible resultan otros modelos de aprendizaje? ¿Cambia el modelo cuando los niños que saben los cantos no van a arriar una vaca o a arriar un lote de ganado?

En consecuencia, predominaba el aprendizaje empírico y memorístico, que dio paso a la adquisición de habilidades, aptitudes y experiencias del trabajo que comprometen un estilo de vida que evidencia expresiones autóctonas como cuentos, cantos, sucesos, vivencias, mitos; lenguaje gestual y corporal, es decir intervienen el cuerpo, la voz, y la emoción, que da cuenta de una semiótica subyacente en el significado que tiene las formas de organización de los llaneros, la interpretación del acontecer de la naturaleza y el sentido de lidiar con el ganado.

Es importante destacar que la enseñanza dirigida a niños y jóvenes se efectuaba mostrando la forma cómo se hacían las labores, felicitando a quienes lo hacían bien y llamándoles la atención o castigando cuando sus trabajos eran poco satisfactorios. Estos estímulos positivos y negativos, permitían al aprendiz adquirir formas de comportamiento apropiadas que iban moldeando poco a poco, les ayudaban a fortalecer la personalidad y carácter propio que tiene fundamentos en la familia, la socialización con los compañeros de faena, la relación con el medio, los vínculos esporádicos con quienes habitaban las posadas ganaderas, sin darse cuenta los papás construían un proceso pedagógico de la enseñanza de las tradiciones.

La pedagogia expresada se puede visibilizar inicialmente desde las siguientes relaciones y jerarquizaciones conceptuales (Figura 4).

Figura 4. Esquema de aprendizaje de los cantos de trabajo de llano

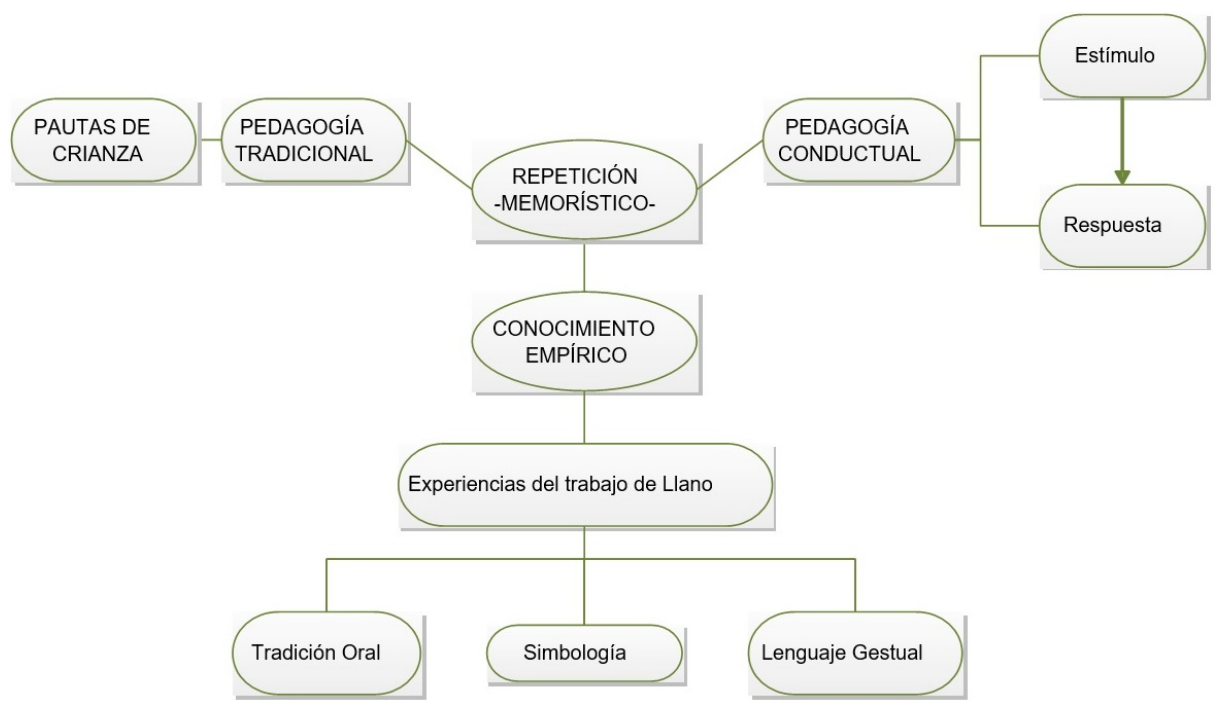

El aprendizaje de los cantos de trabajo del llano, en la mayoría de los casos, se inicia a corta edad cuando los niños están acompañando a sus padres, abuelos $\mathrm{y} / \mathrm{o}$ encargados de la finca al desarrollo de los trabajos cotidianos en el llano, en donde se ejecutan prácticas empíricas cargadas de simbología, gestos, y riqueza oral propia, es la forma tradicional de trabajar. En otras palabras, es un aprendizaje general que, de acuerdo con Bandura, es sinónimo de adquisición de conocimientos a través de la observación, del ejercicio constante, del uso de la memoria, de la interacción social, de la reproducción del conocimiento como la de los adultos, es la respuesta después de estímulos permanentes. 
Como se ha señalado, el saber de los llaneros contiene un universo de conocimientos propios, adquiridos en forma empírica a través de la vida, los cantos hacen parte de la riqueza ancestral que ha aprendido a partir de la observación directa y experiencia colectiva, por esta razón los mismos portadores los han clasificado según su necesidad y aplicación, precisando:

1. Cantos de vela para acompañar el ganado durante la noche.

2. Cantos de ordeño para establecer una relación de apaciguamiento y mansedumbre que facilite la acción de ordeñar.

3. Cantos de arreo para conducir el ganado de forma alineada y evitar su dispersión.

4. Cantos de cabrestero para indicar a la manada que va acompañada y que debe ajilar por el camino que conduce el cabrestero.

Se puede manifestar que es una especie de clasificación que se tenía en cuenta para que dichos cantos fueran entonados en determinada actividad ganadera. Los cantos son constructos que resultan de la práctica permanente y la apropiación de expresiones raizales, mediados por un proceso comunicativo con distintos actores: los llaneros o vaqueros, el ganado, la sabana y el llano biodiverso.

En la encuesta se indagó: ¿Para qué se enseña a las nuevas generaciones los cantos de trabajo del llano? Se destaca que para el 33\% la preservación de la cultura es fundamental porque constituye parte del orgullo de ser llanero. El 28\% cree que la enseñanza es necesaria para que se conozcan las tradiciones y los orígenes del llano. El $15 \%$ define que se requiere la tradición familiar para incentivar el uso de los cantos. El $13 \%$ considera que se puede aprender aprovechando el tiempo libre, esto es importante como alternativa que ha de proteger el patrimonio. El 11\% afirma que nuevos actores sociales pueden interferir en las pautas de crianza y en las formas de vida del llanero, aspecto que es fundamental porque los jóvenes quieren nuevas experiencias y formas de vida (Figura 5).

Figura 5. Para qué se enseña a las nuevas generaciones los cantos de trabajo del llano

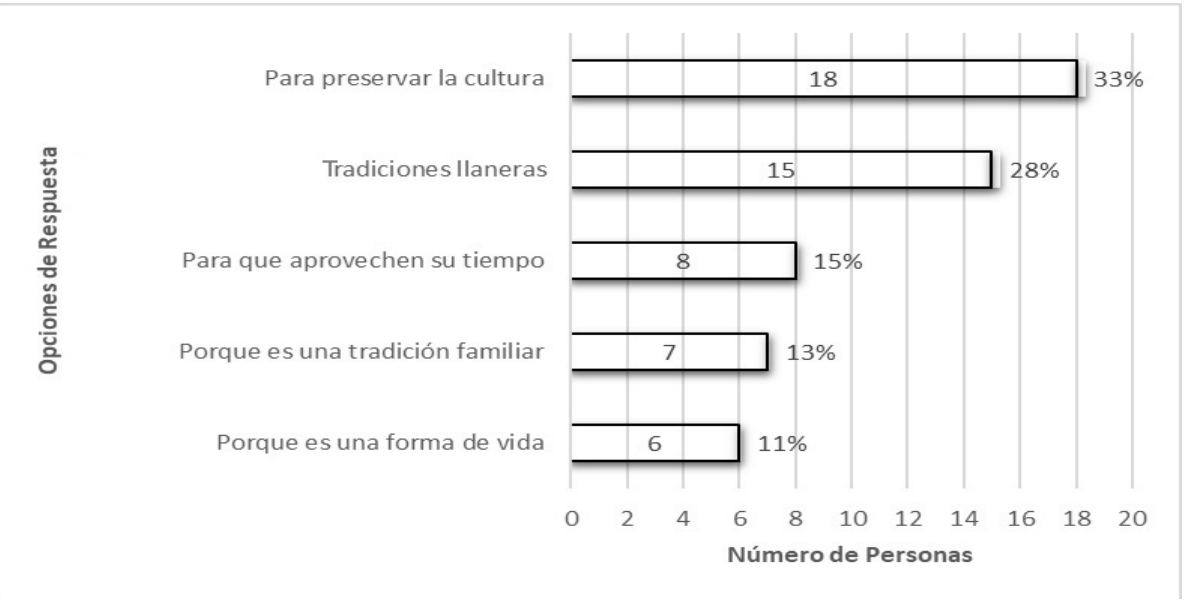

Para las nuevas generaciones, el aprendizaje de los cantos se convierte en hecho significativo cuando cobra sentido para el aprendiz, que pueda expresar en acciones diarias de cada llanero y vivencias cotidianas; cuando participa en estas labores, desarrolla interés y deseo por aprender, se comienza a generar conocimiento que se funda en la 
comunicación que se establece con los animales, y la forma de apaciguarlos, lo cual suscita la creatividad para describir a través del canto, los hechos que suceden con los animales y las relaciones sociales que se establecen entre sí. Por tal motivo, los portadores de los cantos de trabajo del llano cuando realizan las labores propias del llanero construyen cantos a la realidad que viven.

En consecuencia, el portador del canto es un mediador que permite al aprendiz la participación en las actividades de la faena, apropiada por una constante motivación y acompañada por las relaciones afectivas como la mejor forma para transferir sus experiencias, lo que se constituye en aprendizaje nuevo y significativo (Figura 6).

\section{Figura 6. Esquema de un aprendizaje significativo}

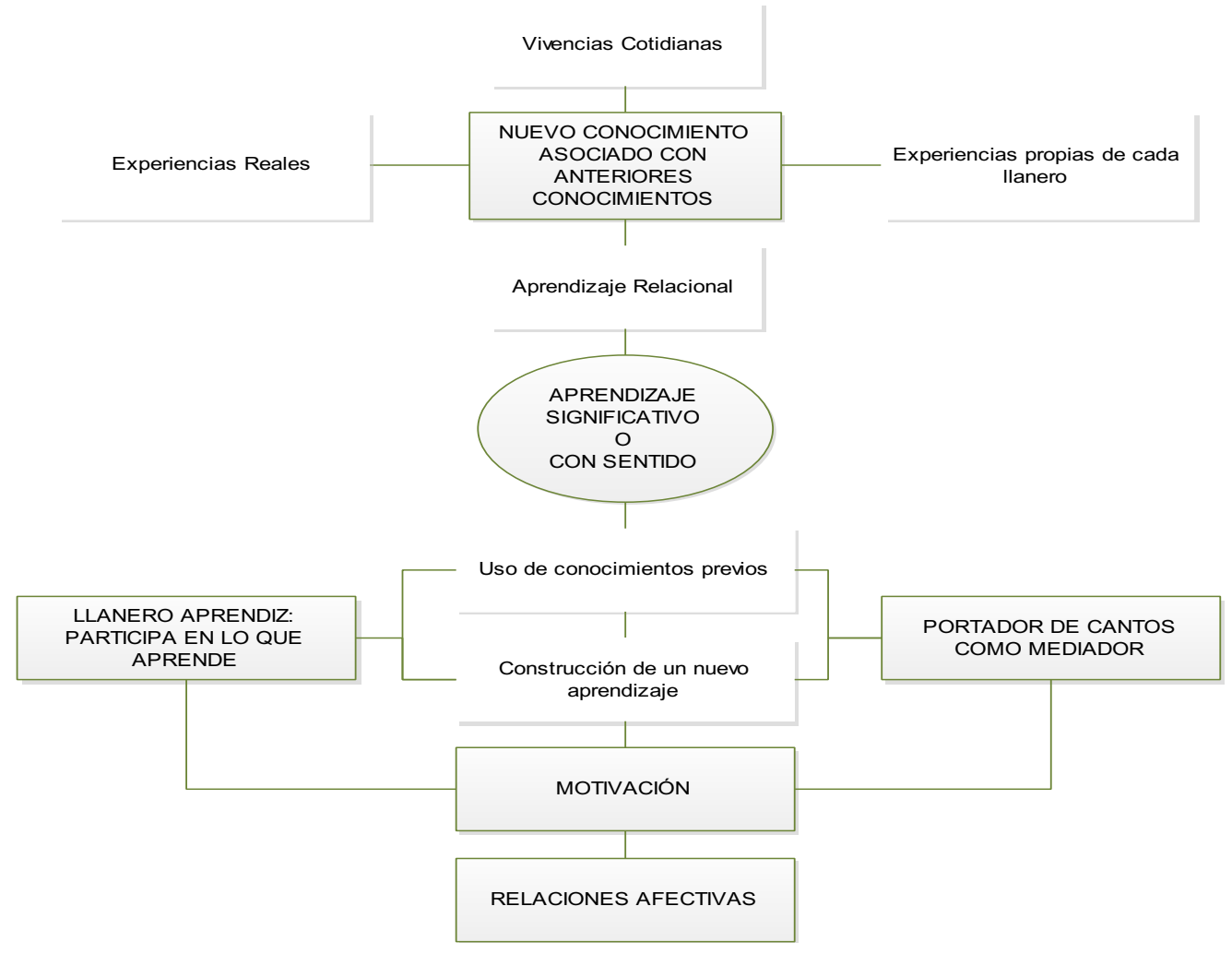

Se subraya en que los individuos que se implican con la comprensión personal, partiendo de su propia experiencia, son el centro del proceso de aprendizaje en donde el resultado debe ser la producción de conocimiento.

\subsection{LA TRANSMISIÓN CULTURAL}

Frente a la pregunta ¿cuál es la fuente de inspiración de los cantos de trabajo del 1lano? Responde un 26\% que tiene correspondencia con la relación del llanero o del portador y las vivencias diarias de su trabajo; un 22\% expresa un sentimiento de arraigo y valor por su raza; un $22 \%$ asegura que los cantos se llevan en la sangre. Coincide un $22 \%$ en resaltar las formas de improvisación de los cantos, versos, poemas, japeos y silbidos, el 19\% es consciente de la cercanía con los animales. Un porcentaje menor que equivale a un $11 \%$ muestra la influencia de los amores y desamores en la inspiración. Todo lo anterior subraya la importancia que se da las vivencias diarias y la interacción con los animales que motiva a los trabajadores a mantener un aprendizaje continuo y 
constituye no solo la asimilación del saber por sí mismo, sino la interacción y repetición con la improvisación de los demás (Figura 7).

\section{Figura 7. Fuentes de inspiración de los cantos de trabajo de llano}

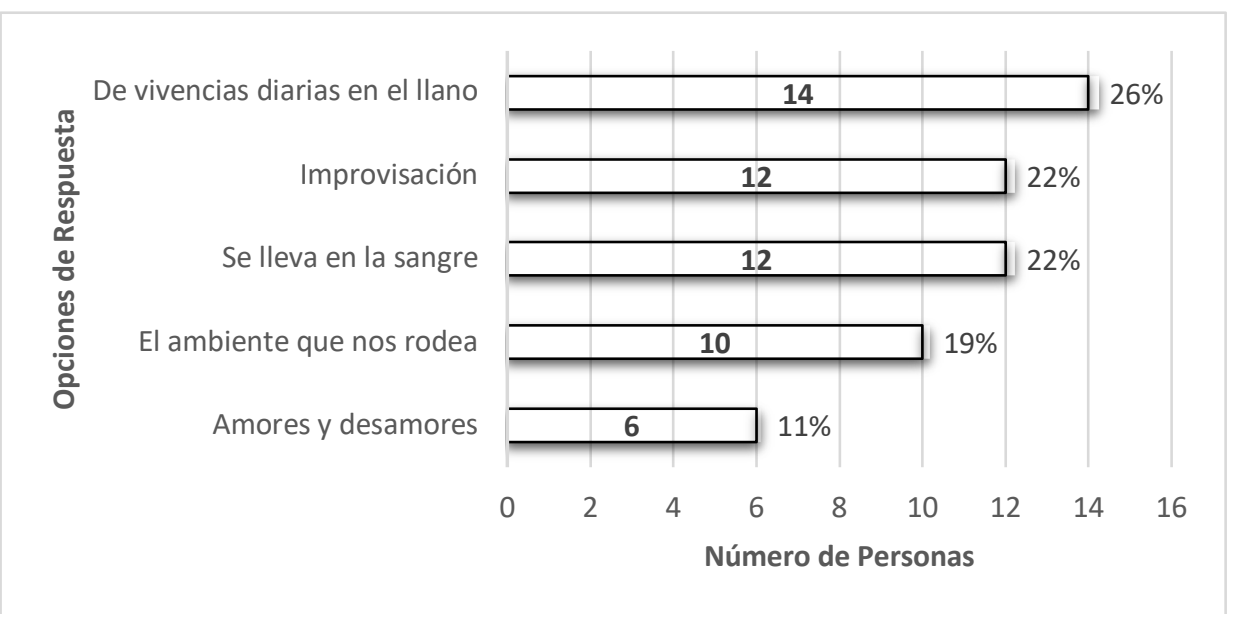

En cuanto a ¿Cuáles son las actitudes al practicar los cantos de trabajo del llano?, la encuesta reveló que el $24 \%$ de los encuestados considera que las actitudes están relacionadas con lo raizal y el arraigo por las costumbres, pues el portador declara que el orgullo de ser llanero se manifiesta en los cantos, por lo recio del trabajo que desempeñan y de considerar su faena diaria como una hazaña. El 22\% cree que se rescata la alegría, la tranquilidad y la armonía en el momento de la interpretación de los cantos por ser la manera como se conduce al ganado por el camino correcto. El 22\% considera que la pasión por la identidad cultural guarda coherencia con el valor que se le da a la cultura y a sus manifestaciones. El 13\% manifiesta el deseo de expresar todos sus sentimientos cuando practica los cantos de trabajo de llano, coincide también en un 13\% respecto a la pujanza y ánimo por la dedicación a su trabajo. El 6\% canta sin ninguna motivación externa al hecho de situarse en el contexto de la faena llanera.

Las actitudes son vistas como relaciones afectivas que se constituyen en motivación para el aprendizaje. La pujanza, el ánimo y las ganas de expresar todos los sentimientos son actitudes propias del portador de los cantos y se establecen como elementos diferenciadores de la cosmovisión de los llaneros raizales (Figura 8).

\section{llano}

Figura 8. Actitudes que se perciben frente al uso de los cantos de trabajo de

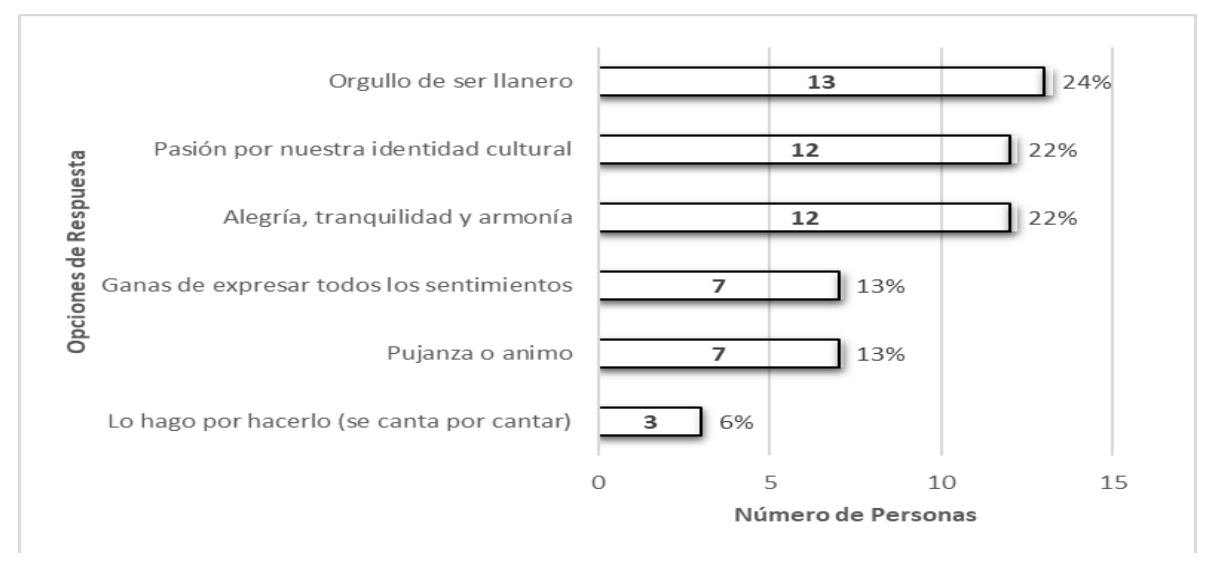


En relación con la pregunta: ¿se transmiten a las nuevas generaciones los cantos de trabajo de llano?, $30 \%$ dicen que se transmiten a través de los años, $26 \%$ mediante la práctica de costumbres culturales desarrolladas a partir de las habilidades y destrezas en el trabajo de 1 lano. 20\% reconocen que los cantos se trasmiten para valorar la cultura llanera como legado cultural de los mayores, lo cual guarda coherencia con la importancia y el status que le da el portador al saber ancestral. 15\% de los portadores manifiestan que para la apropiación de las tradiciones se ve la necesidad de promover en las nuevas generaciones el valor por el acervo cultural. Un bajo porcentaje del $9 \%$ manifiesta orgullo por las costumbres llaneras, lo cual es preocupante porque se está perdiendo el arraigo cultural.

Los bajos porcentajes hallados preocupan a los portadores del conocimiento en razón a que faltan alternativas e institucionalidad que se ocupen de trabajar por el reconocimiento de la memoria colectiva, el fomento y divulgación de las costumbres y tradiciones de la cultura llanera en las agendas familiares, culturales, políticas y sociales (Figura 9).

\section{de llano}

Figura 9. Forma de transmitir a las nuevas generaciones los cantos de trabajo

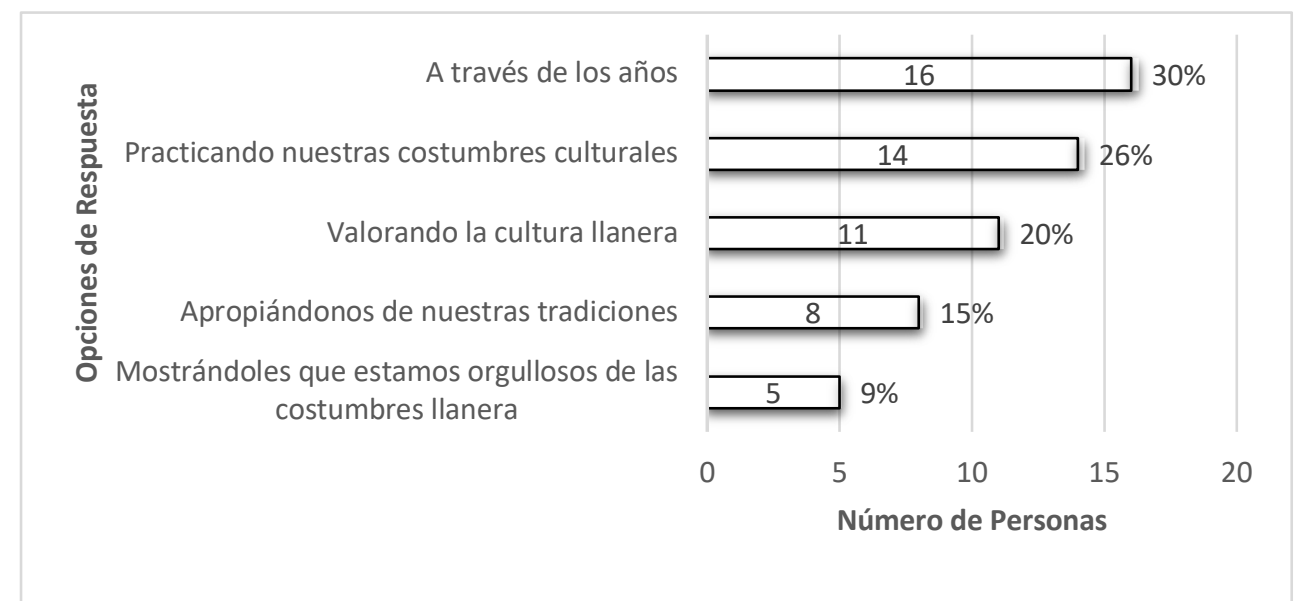

Con respecto a la pregunta: ¿cuáles son las causas de la pérdida de los cantos de trabajo del llano? El 22\% consideran que falta de sentido de pertenencia por la cultura, el $20 \%$ contestan que se está perdiendo esta costumbre por desplazamiento de la actividad ganadera, son dos causas significativas de la pérdida y desuso de los cantos, pues la ausencia de sentimiento por la región y la transformación del contexto, son esenciales para la conservación del patrimonio, finalmente $19 \%$ responden que se están perdiendo debido a la penetración de culturas foráneas. El 17\% consideraron que se está imponiendo la explotación petrolera y el desarrollo tecnológico por tanto no interesan para nada los cantos de trabajo de llano, el 13\% confirman esta pérdida como acelerada, pues se asocian a las nuevas formas de empleo que encuentra el llanero para su subsistencia, para el $9 \%$ la propiedad de las tierras está pasando a otros pobladores que no son de la región y desconocen la cultura de la región (Figura 10). 


\section{Figura 10. Causas de la pérdida de los cantos de trabajo del llano}

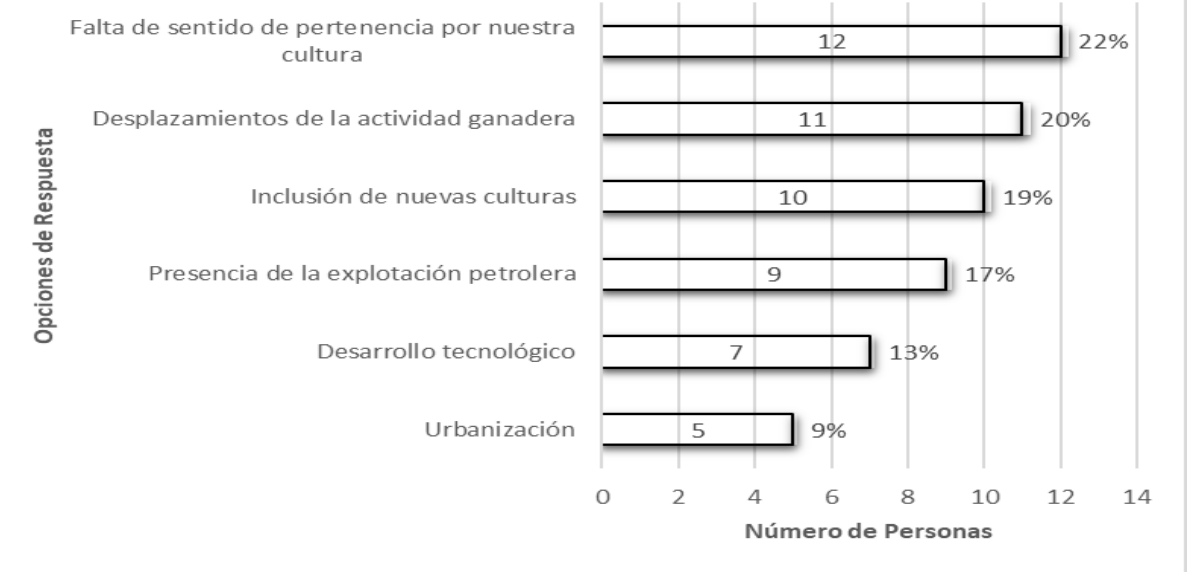

Caracterizar los Cantos de trabajo del llano como patrimonio cultural inmaterial nos convoca a responder sobre ¿qué tipo de producto cultural son los cantos? Son un producto de las vivencias diarias que caracterizan a los llaneros en sus faenas, que alimentan su forma de ser, el valor por su territorio y la espontaneidad de las expresiones que describen las querencias a los animales, a las personas y a la vida; según Pérez (2016: 401) «Aquellos pastores que iban improvisando sus versos en viva voz lo hacían pensando en la capacidad que aquellas improvisaciones podían tener para influir en el mundo que les rodeaba».

Es imperativo para la academia llanera y la sociedad recuperar esta manifestación, que permita abordar el proceso enseñanza-aprendizaje desde la transmisión cultural a partir de los procesos de patrimonialización, a fin de que los niños que viven en el territorio de los llanos orientales colombo-venezolanos, quieran aprender estos cantos en donde también se consoliden valores y creencias contenidas en el saber ancestral, que en términos de Orduna Portús (2012: 426-427) se trata:

De una nueva reinterpretación de la tradición, una praxis de la cultura, una autoafirmación en la diferencia. En definitiva, han sabido adaptar de forma consciente a su sociedad actual aquellos elementos procedentes de su herencia cultural y que han entendido como dignos de conservar.

La transmisión cultural implica un proceso comunicativo que apropia el saber ancestral de los cantos desde las costumbres y tradiciones de la faena llanera, así como el proceso de enseñanza en forma permanente en contexto desde la práctica de las actividades de ordeño, arreo de ganado y otros; el saber empírico, producto de la observación directa del aprendiz y de la observación colectiva dada por los portadores del saber (Figura 12). 
Figura 12. Estructura de la pedagogía como proceso comunicativo de los cantos de trabajo de llano

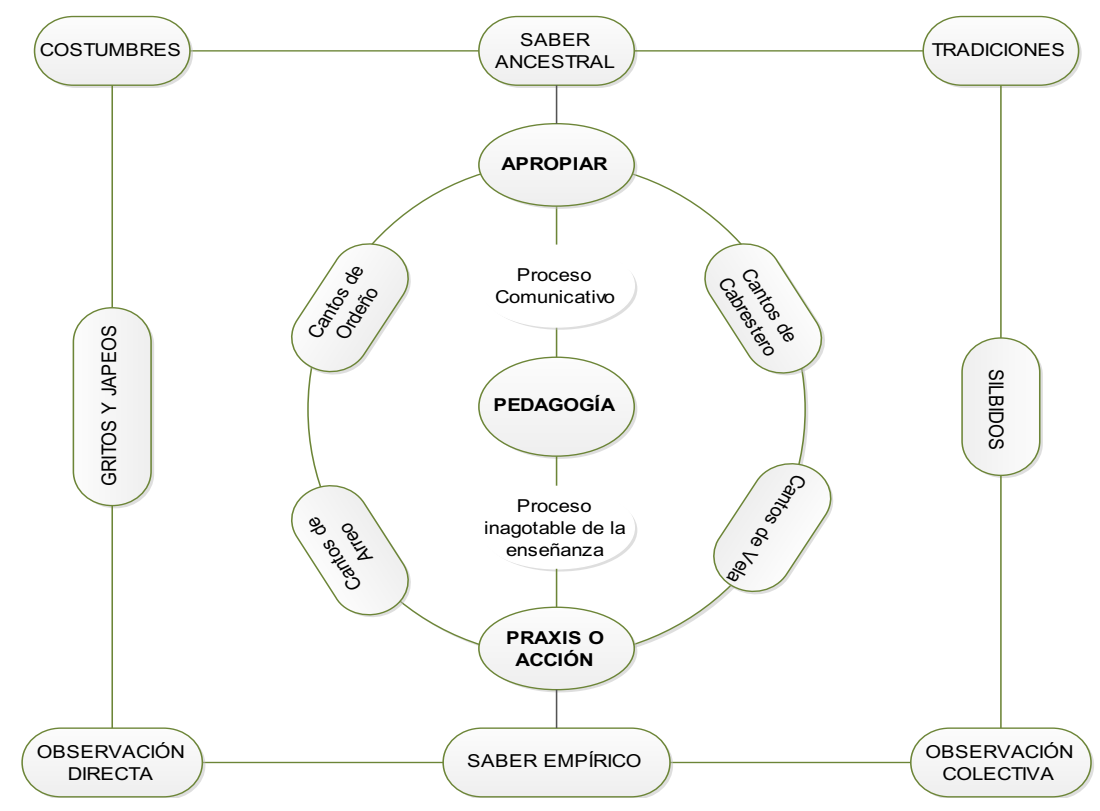

Esta participación colectiva favorece la adquisición y conservación de los saberes ancestrales y permite a los miembros desarrollar aptitudes y actitudes para la construcción y apropiación de los cantos de trabajo del llano.

\section{CONCLUSIONES}

De acuerdo con los hallazgos en la investigación se pueden escribir las siguientes consideraciones frente a los principales riesgos y alcances de la manifestación de patrimonio cultural inmaterial denominada Cantos de Trabajo de Llano:

En la actualidad, los cantos se han perdido porque el trabajo de ganadería ha cambiado sustancialmente, en razón a que ya el ganado no pasta en grandes extensiones, sino en potreros cercados, motivo por el cual las reses caminan por las orillas de los cercados con alambre de púa y para pasar de un corral como antes, se debe abrir un broche que cada propietario ha colocado. Entonces surge la pregunta: ¿Cambia el modelo de enseñanza-aprendizaje cuando los niños que seguramente saben los cantos no van a ordeñar una vaca, ni mucho menos a arriar un lote de ganado?

Los portadores expresan con tristeza que en muy pocas fincas se practican los cantos, los vaqueros ya no se reúnen a ganadear, a herrar, a ordeñar se ha perdido el afecto por los animales. Lo que antes era orgullo e identificaba a los llaneros como sus destrezas para manejar el ganado, cantar cantos de llano, jinetear, adiestrar, es más una añoranza del pasado.

El Plan de Salvaguardia de los Cantos de Trabajo de Llano, hace parte de la política cultural del país y del mundo, representa formas de actuar de los trabajadores y expresiones de las actividades diarias de los llaneros, que guardan coherencia con las cosmovisiones de estos pueblos. La preocupación para iniciar su proceso de salvaguardia está dada por el desuso de los Cantos, producto de las transformaciones de las actividades económicas, distribución territorial de los hatos, fundaciones o fincas; de las formas de transportar el ganado y de la inminente pérdida de los elementos que constituyen la identidad del llanero. 
Este estudio propone una pedagogía significativa que implica la mediación inicial desde las acciones que ejecutan los llaneros en el trabajo de llano, que se traduce en observación, motivación, resignificación e interpretación de cantos, que entre unos y otros parafrasean para concluir con la creación de nuevos cantos y manifestaciones acompañadas de tonalidades y armonías, cuya inspiración principal son los elementos que aporta la naturaleza desde el bramido del ganado, hasta el canto de aves, chicharras, sapos y ranas, araguatos, chechenas, alcaravanes y las guacharacas, entre otros. Este conocimiento tradicional permite consolidar los objetos de estudio a partir de visiones multidisciplinarias que incluye otros campos del saber como la antropología, filosofía, lingüística, gastronomía, las artes y la música, incluso la medicina veterinaria como disciplinas que contribuyen a materializar lo que representan los Cantos de Trabajo del Llano como bien patrimonial inmaterial.

De acuerdo con las propuestas del Ministerio de Cultura de Colombia, el trabajo de llano y sus cantos representan elementos fundamentales en la cultura de los llanos en tres aspectos fundamentales de la salvaguardia para tener en cuenta en su formalización: la creación de un Colectivo de Portadores, representado por los cantadores de ganado, por los viejos que quedan, que se criaron y se formaron cantando ganado, que dé origen a la creación de un modelo pedagógico de enseñanza-aprendizaje del saber para las futuras generaciones. La creación de un Grupo Gestor del PESuC, en el cual pueden participar las organizaciones sociales, los grupos de investigación, los grupos de gestión cultural, las alcaldías locales, los vigías de patrimonio y la comunidad en general, por último, el Comité Interinstitucional principalmente para asesorar y acompañar el proceso de conformación y creación de la Red de Salvaguardia, liderada por las Instituciones que se comprometan con la conservación, protección y preservación del saber ancestral.

¿Qué quiere decir entonces tener bienes declarados o ser patrimonio? ¿Cuál es ese camino que se abre cuando estas manifestaciones son dirigidas a la Orinoquia? ¿Por qué ha sido promulgado como patrimonio de la nación? Ser patrimonio es decirle al país y al mundo que importa el llano, que no hay indiferencia ante la transformación de sus expresiones socioculturales y que se quiere valorar y proteger la riqueza cultural de las comunidades.

Desde el referente identitario del ser llanero, patrimonio es la expresión del profundo valor que se la da al trabajo, lo que implica una relación especial con el territorio, la naturaleza y los animales, desde la recreación de tradiciones musicales con un gran componente de improvisación. Desde la cosmovisión, organización social y el espíritu propio del llanero, los cantos son una herramienta de trabajo que ha dado continuidad y materialidad a un pasado de luchas, adaptaciones y resistencias, que requiere cerrar la fractura generacional de su enseñanza y dar valor al saber ancestral expresado por sus portadores.

\section{REFERENCIAS BIBLIOGRÁFICAS}

Ausubel, David. 1963. The psychology of meaningful verbal learning. New York: Gruneand Stratton.

Bandura, Albert. 1982. Teoría del Aprendizaje Social. Madrid: Espasa Calpe.

Bandura, Albert. 1987. Pensamiento y acción. Fundamentos sociales. Barcelona: Martínez-Roca.

Bortolotto, Chiara. 2014. «La problemática del patrimonio cultural inmaterial». Culturas. Revista de Gestión Cultural, 1(1): 1-22. Recuperado de https://polipapers.upv.es/index.php/cs/article/view/3162 
Contreras Oré, Fabio. 2016. «El aprendizaje significativo y su relación con otras estrategias». Revista Horizonte de la Ciencia, 6(10): 130-140.

DANE. 2017. Geoportal, Georeferenciador de direcciones. Recuperado de https:/geoportal.dane.gov.co/georreferenciador.htm

Díaz, Simón. 1994. Cuenta y Canta. Volumen 1 y 2. Recuperado de https://musicadeoir.wordpre ss.com/2013/06/.../simon-diaz-cuenta-y-canta-vol1-1994/

Estévez, Antonio. 1976. Canto de Ordeño: cantada por Simón Díaz. Recuperado de www.cancioneros.com/nc/6147/0/canto-de-ordeno-antonio-estevez

Garcés C, Mariana, María C. López, Enzo Arigza, Juan L. Isaza, Adriana Molano. 2013. Plan especial de salvaguardia de carácter urgente de los cantos de trabajo de llano. Recuperado de http://www.mincultura.gov.co/prensa/noticias/Documents/ Patrimonio/15Cantos\%20de\%20trabajo\%20de\%20Llano\%20-\%20PES.pdf

González, Reinaldo. 2007. Perspectivas de la tonada llanera en el ámbito comunicacional. Caracas: Universidad Central de Venezuela, Facultad de Humanidades y Educación, Escuela de Comunicación Social.

Martí Contreras, Jorge y Martha Valls Lafuente. 2009. «Motivación y juego en el aula: La implicación del alumno en las clases de E/LE». Foro de Profesores de E/LE, 5: $1-10$.

Ministerio de Cultura de Colombia. 2014. Resolución 054 del 08 de enero de 2014. Recuperado

de http://www.mincultura.gov.co/prensa/noticias/Documents/Patrimonio/15Resoluc ion \%20Cantos\%20de\%20Trabajo\%20de\%20LLano.pdf

Orduna Portús, Pablo. 2012. «End of the trail: Los últimos pastores roncaleses en las montañas de Nevada (EE. UU.)». Revista de dialectología y tradiciones populares, 67(2): 409-430.

Pérez Radziunas, Andrea Danute. 2014. El territorio de los cantos de trabajo de llano: espacialización de una manifestación inmaterial. Tesis doctoral. Bogotá: Pontificia Universidad Javeriana. Recuperado de https://repository.javeriana.edu.co

Pérez Reig, Laura. 2017. Outdoor Educación: Una Forma de Aprendizaje Significativo. Sevilla: Editor S.L. Punto Rojo Libros.

Pérez, Pío. 2017. «El canto del pastor no espanta las ovejas: memoria y nostalgia en los versos improvisados de los emigrantes vascos». Revista de Dialectología y Tradiciones Populares, 71(2): 389-414.

Quintana Albatat Jordi y Oscar Yesid Aparicio Gómez. 2017. Temas emergentes de la educación ( $1^{\mathrm{a}}$ ed.). Bogotá: Universidad Central.

Radio Nacional de Colombia. RTVC - Sistema de medios públicos. 2014. Entrevista al poblador del llano Víctor Espinel, considerado llanero faculto. Recuperado de https://www.radionacional.co/noticia/v-ctor-espinel-un-llanero-ciento-porciento-en-el-atardecer

Rivera Arenas, Carlos Andrés. 2010. «Cultura Musical Llanera Urbana, un Imaginario que se Construye en las ciudades del piedemonte». Pensamiento, palabra y obra, 3: 12-23. Recuperado de http://dx.doi.org/10.17227/ppo.num3-433

Salazar, Rafael. 2000. El Mundo Árabe en Nuestra Música. Fundación Tradiciones Caraqueñas: Caracas.

UNESCO. 2017. Decimosegunda sesión del Comité de Salvaguardia para el Patrimonio Cultural Inmaterial. Decisión del Comité intergubernamental: 12.COM.11.a.2. Recuperado de https://ich.unesco.org/es/Decisiones/12.COM/11.a.2. 


\section{APÉNDICES}

Apéndice A: Formato de Entrevista

\begin{tabular}{|c|c|c|c|c|c|c|}
\hline PROYEC & $\begin{array}{r}\text { O: PRO } \\
\text { DE }\end{array}$ & $\begin{array}{l}\text { FORM } \\
\text { OS DE E } \\
\text { S CANT }\end{array}$ & $\begin{array}{l}\text { DE EN } \\
\text { ẼNANZ } \\
\text { DE TR }\end{array}$ & $\begin{array}{l}\text { REVISTA } \\
\text { APREND } \\
\text { AJO DE }\end{array}$ & $\begin{array}{l}\text { EN I } \\
\text { O }\end{array}$ & EGADO \\
\hline & & eguntas & dentific & ión Perso & & \\
\hline Nombres y & pellidos & & & & & \\
\hline Documento & de Identifi & & & & & \\
\hline Lugar de $\mathrm{N}$ & cimiento & & & Lugar de & lencia & \\
\hline Ocupación & & & & Residenc & & \\
\hline Género & & Edad & & Número & ico & \\
\hline $\begin{array}{c}\text { Nivel de } \\
\text { Formación }\end{array}$ & Pria. & Bach. & $\begin{array}{l}\text { Téc. o } \\
\text { Tecn. }\end{array}$ & Prof. & Esp. & $\begin{array}{c}\text { Ninguno } \\
\text { de los } \\
\text { anteriores }\end{array}$ \\
\hline $\mathbf{N}^{\circ}$ & & & & untas & & \\
\hline 1 & $\begin{array}{l}\text { ¿Tiene } \mathrm{u} \\
\text { cantos de }\end{array}$ & $\begin{array}{l}\text { conocim } \\
\text { ajo de } 11\end{array}$ & de la $\mathrm{m}$ & era de cón & an trar & tido los \\
\hline 2 & ¿Cómo a & dió los c & de trab & de llano? & & \\
\hline 3 & $\begin{array}{l}\text { ¿Qué mé } \\
\text { llano? }\end{array}$ & s utiliza & para la & señanza d & antos c & bajo de \\
\hline 4 & $\begin{array}{l}\text { ¿Ha ense } \\
\text { cantos? }\end{array}$ & los cant & trabajo & llano? ¿ & enseñ & usted los \\
\hline 5 & $\begin{array}{l}\text { ¿Los ofic } \\
\text { saber anc }\end{array}$ & $\begin{array}{l}\text { que desar } \\
\text { l de los }\end{array}$ & $\begin{array}{l}\text { en los } \\
\text { os de tra }\end{array}$ & $\begin{array}{l}\text { os, contril } \\
\text { o de llano }\end{array}$ & a que & endiera el \\
\hline 6 & ¿ Existe & proceso & a crear 1 & cantos? & & \\
\hline 7 & $\begin{array}{l}\text { ¿Existe a } \\
\text { interpret }\end{array}$ & $\begin{array}{l}\text { prepara } \\
\text { cantos }\end{array}$ & $\begin{array}{l}\text { (silbidos } \\
\text { abajo de }\end{array}$ & $\begin{array}{l}\text { apeos, gr } \\
\text { no? }\end{array}$ & ros) 1 & para \\
\hline 8 & $\begin{array}{l}\text { ¿Nos pue } \\
\text { de llano? }\end{array}$ & ontar alg & reseña h & órica refer & los car & de trabajo \\
\hline 9 & ¿sabe ust & orque se & inta al ge & do? & & \\
\hline 10 & $\begin{array}{l}\text { ¿Cuáles } \\
\text { llano? }\end{array}$ & dera uste & e son lo & eneficios & to en & bajo de \\
\hline 11 & $\begin{array}{l}\text { ¿Qué cla } \\
\text { distintos }\end{array}$ & $\begin{array}{l}\text { temátic } \\
\text { de los c }\end{array}$ & $\begin{array}{l}\text { relatos s } \\
\text { s de trab }\end{array}$ & $\begin{array}{l}\text { ueden dar } \\
\text { de llano? }\end{array}$ & diálog & le los \\
\hline 12 & $\begin{array}{l}\text { ¿Qué nos } \\
\text { trabajo d }\end{array}$ & $\begin{array}{l}\text { nseja ust } \\
\text { no? }\end{array}$ & ara prese & ar el sabe & tral de & cantos de \\
\hline 13 & $\begin{array}{r}\text { ¿Consid } \\
\text { y consec }\end{array}$ & $\begin{array}{l}\text { ue se ha } \\
\text { las? }\end{array}$ & ido este & ber? ¿Nos & decir & nas causas \\
\hline
\end{tabular}

Apéndice B: Formato de Encuesta 


\begin{tabular}{|c|c|c|c|c|c|c|c|}
\hline PROY & $\begin{array}{l}\text { ECTO } \\
\text { LEGA }\end{array}$ & $\begin{array}{r}\text { FC } \\
\text { PROCE } \\
\text { O DE LC }\end{array}$ & $\begin{array}{l}\text { MATC } \\
\text { S DE I } \\
\text { CANT }\end{array}$ & $\begin{array}{l}\text { DE EN } \\
\text { NSEÑA } \\
\text { OS DE }\end{array}$ & $\begin{array}{l}\text { UEST } \\
\text { NZA-A } \\
\text { RABA }\end{array}$ & $\begin{array}{l}\text { RENDIZAJ } \\
\text { O DE LLAN }\end{array}$ & $\begin{array}{l}\text { EN EL } \\
\text { O }\end{array}$ \\
\hline & PRI & GUNTAS & E IDE & TIFIC & CIÓN & ERSONAL & \\
\hline $\begin{array}{l}\text { Nombres y } \\
\text { Apellidos }\end{array}$ & & & & & & & \\
\hline Documento & de Ider & ificación & & & & & \\
\hline $\begin{array}{l}\text { Lugar de } \\
\text { Nacimiento }\end{array}$ & & & Lugar & e Proce & encia & & \\
\hline Ocupación & & & Reside & cia Act & & & \\
\hline Género & & Edad & & $\begin{array}{l}\text { Númer } \\
\text { teléfon }\end{array}$ & & & \\
\hline $\begin{array}{l}\text { Nivel de } \\
\text { Formación }\end{array}$ & Pria. & Bach. & $\begin{array}{c}\text { Téc. } \\
\text { o } \\
\text { Tecn. }\end{array}$ & Prof. & Esp. & $\begin{array}{c}\text { Ninguna de } \\
\text { las } \\
\text { anteriores }\end{array}$ & Otro \\
\hline $\mathrm{N}^{\circ}$ & & & PRE & $\overline{\mathrm{UNTA}}$ & & & $\begin{array}{l}\text { RESPUEST } \\
\text { A }\end{array}$ \\
\hline En las & guie & s pregun & $\begin{array}{l}\text {, elija } \\
\text { im }\end{array}$ & $\begin{array}{l}\text { a de la } \\
\text { ortante. }\end{array}$ & tern & as que consi & lere más \\
\hline MANER & $\mathrm{AS} \mathrm{Y/C}$ & FORMA & $\begin{array}{l}\text { ARA I } \\
\text { RABA. }\end{array}$ & $\begin{array}{l}\text { APRF } \\
\text { DE L }\end{array}$ & $\begin{array}{l}\text { JDIZA } \\
\text { ANO }\end{array}$ & DE LOS C & NTOS DE \\
\hline 1 & $\begin{array}{l}\text { ¿Cuál } \\
\text { enseñ }\end{array}$ & $\begin{array}{l}\text { s fueron } 1 \\
\text { nza de los }\end{array}$ & $\begin{array}{l}\text { medios } \\
\text { antos d }\end{array}$ & $\begin{array}{l}\text { mecar } \\
\text { Trabaj }\end{array}$ & $\begin{array}{l}\text { smos p } \\
\text { del L }\end{array}$ & $\begin{array}{l}\text { ra la } \\
\text { no? }\end{array}$ & \\
\hline & a. $\mathrm{Ar}$ & is padres & buelos & & & & \\
\hline & b. An & igos/Cono & dos/Vec & & & & \\
\hline & c. $\mathrm{Pal}$ & tas de cria & & & & & \\
\hline & d. Em & jíricamen & & & & & \\
\hline & e. $\mathrm{Co}$ & tumbre & & & & & \\
\hline 2 & ¿Cóm & aprendió & s Cant & de Tra & ajo de & lano? & \\
\hline & $\begin{array}{l}\text { a. } \operatorname{Re} \\
\text { Conte }\end{array}$ & $\begin{array}{l}\text { lizando ac } \\
\text { xto }\end{array}$ & idades & Traba & de Ll & io en & \\
\hline & b. En & as práctic & de la fa & ha llane & & & \\
\hline & c. Par & fraseando & imitanc & los car & & & \\
\hline & d. Ap & endí empí & amente & & & & \\
\hline & e. $\mathrm{Co}$ & tumbre & & & & & \\
\hline 3. & ¿Qué & ipo de car & s le ens & ñaron y & existí & & \\
\hline & a. $\mathrm{Cal}$ & tos para 11 & lar el go & ado a 1 & saler & & \\
\hline & b. $\mathrm{Ca}$ & tos de $\mathrm{Va}$ & ería & & & & \\
\hline & c. $\mathrm{Cal}$ & tos de $\mathrm{Cak}$ & stero & & & & \\
\hline & d. $\mathrm{Ca}$ & tos de $\mathrm{Bec}$ & rero & & & & \\
\hline & e. $\mathrm{Cal}$ & tos de Orc & & & & & \\
\hline & f. Car & os de Vel & & & & & \\
\hline 4. & $\begin{array}{l}\text { ¿Qué } \\
\text { de la }\end{array}$ & $\begin{array}{l}\text { ipos de si } \\
\text { aena llane }\end{array}$ & dos le e & señaror & para la & actividades & \\
\hline & a. Sill & idos para & & & & & \\
\hline & b. Sil & idos para & bajar cc & caball & & & \\
\hline & c. Sill & idos para & & & & & \\
\hline & d. Sil & idos de ve & & & & & \\
\hline
\end{tabular}




\begin{tabular}{|c|c|c|}
\hline \multirow[t]{6}{*}{5} & $\begin{array}{l}\text { ¿ A qué edad comienza a aprender los Cantos de Trabajo } \\
\text { de Llano? }\end{array}$ & \\
\hline & a. Desde su gestación & \\
\hline & b. Desde que nace & \\
\hline & $\begin{array}{l}\text { c. Desde el inicio de participación en las actividades } \\
\text { llaneras (a los } 5 \text { años) }\end{array}$ & \\
\hline & $\begin{array}{l}\text { d. Cuando se integra a las actividades del Trabajo de } \\
\text { Llano (a los } 12 \text { años) }\end{array}$ & \\
\hline & e. Cuando se es adulto & \\
\hline \multicolumn{3}{|c|}{$\begin{array}{l}\text { MANERAS Y/O FORMAS DE PRACTICAR LOS CANTOS DE TRABAJO DE } \\
\text { LLANO }\end{array}$} \\
\hline \multirow[t]{6}{*}{6} & $\begin{array}{l}\text { ¿Cuándo practicaba o practica los Cantos de Trabajo de } \\
\text { Llano? }\end{array}$ & \\
\hline & a. Al observar la puesta del atardecer & \\
\hline & b. Después de las labores llaneras & \\
\hline & $\begin{array}{l}\text { c. Durante el desarrollo de las labores llaneras (ordeño, } \\
\text { herraje, adiestramiento, al dar de beber al ganado, al dar } \\
\text { sal al ganado, otros.) }\end{array}$ & \\
\hline & $\begin{array}{l}\text { d. Durante el Trabajo de Llano (traslado de ganado de } \\
\text { un lugar a otro) }\end{array}$ & \\
\hline & e. Otras. Cuáles?: & \\
\hline \multirow[t]{6}{*}{7} & ¿A quién se les cantaba y/o se les canta? & \\
\hline & a. Al ganado & \\
\hline & b. Al caballo & \\
\hline & c. A la vida & \\
\hline & d. A la sabana & \\
\hline & e. A las actividades rutinarias & \\
\hline \multirow[t]{6}{*}{8} & ¿Por qué se cantaba o se canta a los animales? & \\
\hline & a. Muestra de cariño & \\
\hline & b. Para tranquilizarlos & \\
\hline & c. Para adiestrarlos & \\
\hline & $\begin{array}{l}\text { d. En el caso de la vaca, para que produzcan mayor } \\
\text { cantidad de leche }\end{array}$ & \\
\hline & e. Tener el control de los animales & \\
\hline \multirow[t]{5}{*}{9} & ¿A qué edad del animal se inicia a cantarle? & \\
\hline & a. Recién nacidos & \\
\hline & b. A los tres (3) meses & \\
\hline & c. Al comenzar la edad productiva & \\
\hline & d. No interesa la edad & \\
\hline \multirow[t]{6}{*}{10} & $\begin{array}{l}\text { ¿De dónde nace la inspiración de los Cantos de Trabajo } \\
\text { de Llano? }\end{array}$ & \\
\hline & a. De vivencias diarias en el llano & \\
\hline & b. Se lleva en la sangre & \\
\hline & c. El ambiente que nos rodea & \\
\hline & d. Amores y desamores & \\
\hline & e. Improvisación & \\
\hline 11 & $\begin{array}{l}\text { ¿Qué actitud expresa al realizar o practicar los cantos en } \\
\text { su diario vivir de llanero? }\end{array}$ & \\
\hline
\end{tabular}




\begin{tabular}{|c|c|c|}
\hline & a. Alegría, tranquilidad y armonía & \\
\hline & b. Pujanza o ánimo & \\
\hline & c. Orgullo de ser llanero & \\
\hline & d. Pasión por nuestra identidad cultural & \\
\hline & e. Ganas de expresar todos los sentimientos & \\
\hline & f. Lo hago por hacerlo (se canta por cantar) & \\
\hline 12 & $\begin{array}{l}\text { ¿En qué actividades complementarias se usan los Cantos } \\
\text { de Trabajo de Llano? }\end{array}$ & \\
\hline & a. En las tertulias o fiestas de amigos & \\
\hline & b. Cuando participo en festivales & \\
\hline & $\begin{array}{l}\text { c. Cuando participa en festivales de o concursos de } \\
\text { vaquería }\end{array}$ & \\
\hline & d. En la composición de las canciones llaneras & \\
\hline & e. En las conquistas o para enamorar & \\
\hline & $\begin{array}{l}\text { f. En las diferentes actividades con el ganado y las } \\
\text { bestias }\end{array}$ & \\
\hline & MAS DE ENSEÑAR LOS CANTOS DE TRABAJO DE I & LANO \\
\hline 13 & $\begin{array}{l}\text { ¿A quiénes se enseña hoy los Cantos de Trabajo de } \\
\text { Llano? }\end{array}$ & \\
\hline & a. A los hijos & \\
\hline & $\begin{array}{l}\text { b. A las personas con quien comparte las labores del } \\
\text { llano }\end{array}$ & \\
\hline & c. A personas que buscan la enseñanza de los cantos & \\
\hline & d. A cantantes & \\
\hline & e. No enseño los cantos & \\
\hline 14 & $\begin{array}{l}\text { ¿Cómo enseña a sus hijos o a las nuevas generaciones } \\
\text { los Cantos de Trabajo de Llano? }\end{array}$ & \\
\hline & a. Realizando actividades de Trabajo de Llano & \\
\hline & b. Cuando se arrea el ganado en el trabajo & \\
\hline & c. Por imitación y repetición & \\
\hline & d. En las escuelas llaneras & \\
\hline & e. Por medio de la experiencia o la práctica de los cantos & \\
\hline 15 & $\begin{array}{l}\text { ¿Para qué o porqué enseña a las nuevas generaciones los } \\
\text { Cantos de Trabajo de Llano? }\end{array}$ & \\
\hline & a. Para preservar la cultura & \\
\hline & b. Porque es una forma de vida & \\
\hline & c. Porque es una tradición familiar & \\
\hline & d. Para que conozcan las tradiciones llaneras & \\
\hline & e. Para que aprovechen el tiempo & \\
\hline 16 & $\begin{array}{l}\text { ¿Cómo motiva a los jóvenes a practicar los Cantos de } \\
\text { Trabajo de Llano? }\end{array}$ & \\
\hline & $\begin{array}{l}\text { a. Concientizando a las nuevas generaciones sobre esta } \\
\text { práctica }\end{array}$ & \\
\hline & b. Por medio de la práctica constante de este saber & \\
\hline & $\begin{array}{l}\text { c. Motivándolos e inscribiéndolos en concursos donde se } \\
\text { compite por la mejor interpretación de los cantos }\end{array}$ & \\
\hline & $\begin{array}{l}\text { d. demostrando que estos cantos los interpretan grandes } \\
\text { cantautores de la música llanera }\end{array}$ & \\
\hline
\end{tabular}




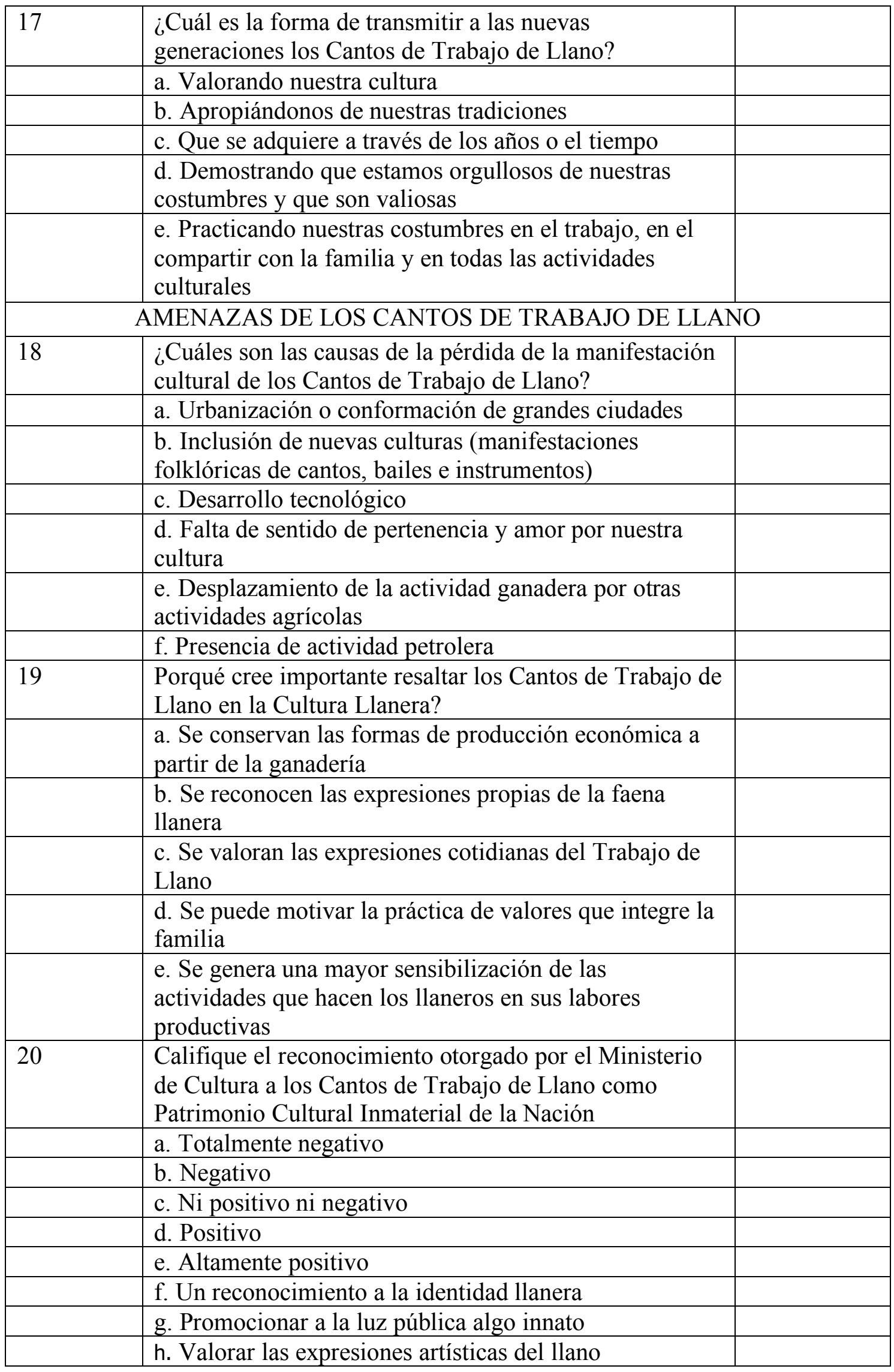

